\title{
Desempenho acústico de painéis de gesso incorporados com fibras de celulose
}

\author{
Acoustic performance of embedded gypsum panels with cellulose fibers
}

\author{
Sâmique Kyene de Carvalho Araujo ${ }^{1}$, Diego Rodrigues de Oliveira², Tiago José da Silva ${ }^{3}$, \\ Juliana Cortez Barbosa ${ }^{4}$ e Maristela Gava ${ }^{5}$ \\ ${ }^{1}$ Mestranda em Engenharia Mecânica pala FEG, Universidade Estadual Paulista, SP, Brasil \\ ${ }^{2}$ Graduando em Engenharia Industrial Madeireira, Universidade Estadual Paulista, SP, Brasil \\ ${ }^{3}$ Mestrando em Ciências Ambientais, Universidade Estadual Paulista, SP, Brasil \\ ${ }^{4}$ Professora Assistente Doutora pela Universidade Estadual Paulista, SP, Brasil \\ ${ }^{4}$ Professor, Doutor, Universidade Estadual Paulista, SP, Brasil
}

\begin{abstract}
Resumo
Atualmente, com a racionalização do consumo de matéria prima em decorrência de possíveis restrições energéticas e danos ao meio ambiente, tem-se buscado maximizar a sua empregabilidade. O setor florestal-madeireiro é um dos grandes responsáveis pela geração de resíduos, os quais devem ser destinados adequadamente para não levar a danos ambientais. Dessa maneira, este trabalho teve como objetivo avaliar o desempenho acústico de painéis fabricados com gesso incorporados com fibras de celulose, provenientes de uma empresa de celulose e papel do Sudoeste Paulista. A avaliação foi efetuada com base na absorção acústica no material, obtendo-se coeficientes de absorção acústica em torno de 0,99 de acordo com valores encontrados em literatura.
\end{abstract}

Palavras-chave: Coeficiente de absorção acústica. Fibras de celulose. Gesso. Painel.

\begin{abstract}
Currently, with the rationalization of consumption of raw materials due to energy constraints and possible damage to the environment, it has tried to maximize their employability. The forestry - wood sector is largely responsible for the generation of waste, which must be allocated appropriately to not lead to environmental damage. Thus, this study aimed to evaluate the acoustical panels made of plaster embedded with cellulose fibers from a pulp and paper company of the Paulista West. The evaluation was made based on the sound absorption material, resulting in sound absorption coefficients at around $X$, according to values found in literature.
\end{abstract}

Keywords: Sound absorption coefficient . Cellulose fibers . Plaster. Panel. 


\section{Introdução}

A madeira é um recurso natural renovável que está presente em abundância na natureza. Foi um dos primeiros materiais manipulados pelo homem sendo empregados na confecção de armas, equipamentos de meio de transporte, em habitações e no aquecimento próprio e de alimentos. Atualmente a madeira é utilizada como matéria prima para atender as necessidades da vida moderna do homem, como por exemplo, na produção de celulose e papel, carvão, painéis, móveis, pequenos objetos e na construção civil.

Todo processo industrial madeireiro, do corte da árvore ao produto final gera uma grande quantidade de resíduos, que infelizmente é descartado ou usado de forma inadequada pelas indústrias, podendo trazer graves problemas ao meio ambiente a até mesmo ao homem. De acordo com o IBAMA (2002) as indústrias madeireiras aproveitam apenas 30\% a $60 \%$ de toda a árvore.

Tradicionalmente os fins mais comuns dos resíduos de madeira são: produção de energia através da queima, forragem de piso, uso doméstico, produção de carvão, entre outros, (TEIXEIRA, 2005).

A celulose, matéria prima para a fabricação de papel, é obtida em grandes volumes diários chegando a toneladas de polpa celulósica branqueada por dia, a qual maioria é exportada. O principal processo de cozimento efetuado no mundo é o conhecido processo Kraft, que ao final gera como resíduo as fibras de celulose que não alcançaram a qualidade exigida para exportação.

A celulose é um carboidrato que forma longas cadeias constituindo as fibras. Essas fazem parte da constituição anatômica da madeira, como a função principal de sustentação mecânica. A morfologia das fibras varia entre espécies, entre árvores e dentro de uma mesma árvore por meio das taxas de crescimento e idade das árvores, podendo ser controladas geneticamente ou fenotipicamente, pelas influências ambientais (METCALFE; CHALK, 1989).

Segundo a Norma Brasileira NBR 10004/2004 - Resíduos Sólidos - Classificação (ABNT, 2004), os resíduos sólidos são aqueles que provenientes de atividade de origem industrial, doméstica, hospitalar, comercial, agrícola, de serviços e de varrição. Sendo classificados como Resíduos Classe I (perigosos), Resíduos Classe II A (não perigosos e não inertes) e Resíduos Classe II B (não perigosos e inertes).

De acordo com a NBR 10004/2004, os resíduos de fibras podem ser classificados como Resíduos Classe II A, por não serem perigosos nem inertes. O resíduo produzido por pelas indústrias de celulose e papel podem ser incorporados em painéis à base de gesso, pois melhoram as propriedades do material, mecânicas: resistência à tração, à flexão, ao impacto e acústicas e térmicas em virtude do aumento da capacidade de absorver energia (OLIVEIRA, 2009).

O gesso também conhecido como gipsita, é um material abundante na natureza, cuja fórmula química é CaSO4.2H2O com maior utilização na construção civil (LYRA SOBRINHO et.al., 2001). O mineral gipsita é uma rocha sedimentar que tem sua origem na precipitação de sulfatos de cálcio contidos em águas marinha submetidas à evaporação, ocorrendo geralmente associadas à anidrita e algumas impurezas (OLIVEIRA, 2009).

Segundo Levy Neto e Pardini (2006), o uso de fibras naturais na produção de compósitos possuem as vantagens de terem baixa massa específica, maciez e abrasividade reduzidas, baixo custo, são recicláveis, não tóxicas, biodegradáveis e possuem baixo consumo de energia na produção. Mas como desvantagens: baixas temperaturas de processamento, acentuada variabilidade das propriedades mecânicas, baixa estabilidade dimensional, alta sensibilidade a efeitos ambientais (temperatura, umidade etc.), as de origem vegetal sofrem significativas influências referentes ao solo, à época da colheita, ao processamento após a colheita e à localização relativa do corpo da planta e propriedades mecânicas modestas em relação aos materiais estruturais tradicionais. 
Baltar et al. 2005, relata que a gipsita proveniente de Araripina, no Estado de Pernambuco é a gipsita de melhor qualidade do mundo, apresentando teores de pureza de 90 a $95 \%$.

O maior produtor e consumidor mundial de gipsita é liderado pelo Estados Unidos. Já o Brasil possui a maior reserva mundial de gipsita, mas representa apenas 1,5\% da produção mundial. A maior produção no país provém de Pernambuco com 1.711.671toneladas por ano, correspondendo a $89 \%$ da produção nacional (LYRA SOBRINHO et.al., 2001).

Segundo Magalhães (2009) é comercializado placas de uso comum, placas resistentes à umidade (com aditivo como o silicone e cartão hidrofungante), placas resistentes ao fogo (adição de vermiculita a fibras de vidro).

A determinação das propriedades físicas do gesso são normalizados pela Norma Brasileira NBR 13207/1994 - Gesso para construção civil, a qual especifica metodologias de ensaios para caracterização do gesso.

A absorção sonora é a capacidade que os materiais possuem de poder transformar parte da energia sonora em outra forma de energia, geralmente a térmica (MEHTA e ROCAFORT, 1999). O coeficiente de absorção sonora $(\alpha)$, é a razão entre a quantidade de energia sonora que é absorvida por determinado material e aquela que sobre ele incide sobre sua superfície.

A absorção acústica trata do fenômeno que minimiza a reflexão das ondas sonoras em um mesmo ambiente. Ou seja, reduz o nível de reverberação (que é uma variação do eco) num mesmo ambiente. Nestes casos se deseja, além de diminuir os níveis de pressão sonora do próprio recinto, melhorar o nível de inteligibilidade. (PATRAQUIM; LUZ; PATRÍCIO, 2012).

Quase todo material cuja superfície é porosa pode ser considerado um absorvente poroso. A porosidade do material se deve à composição fibrosa ou aos vácuos entre os grânulos ou partículas do material (METHA e MONTEIRO, 1994). Madeiras e seus derivados como os painéis são exemplos de materiais porosos. A onda sonora entra pelos poros absorvedores e faz com que o ar nos vácuos do material vibre para frente e para trás, gerando atrito entre as partículas de ar e as paredes, que converte a energia vibracional em calor. Para que ocorra o atrito é necessário que os espaços vazios do material sejam interconectados e contínuos, de modo que o ar possa se mover para frente e para trás no interior do material.

As placas de isolamento acústico são geralmente perfuradas e elaboradas com fibras de madeira, as quais são lavadas, prensadas, secas e depois submetidas a tratamentos químicos especiais, contendo milhares de células de ar. Estas, juntamente com as perfurações absorvem o som; apresentando vantagens como o alto coeficiente de absorção acústica e luminosa, podendo ser pregado e serrado sem o perigo de lascar, sendo que o seu pouco peso permite também que seja colado (CAZELOTO e TAMANINI, 2003).

Como a acústica de recintos depende da geometria das peças, a qual repercute na frequência e no ângulo de reflexão do som (MORESCHI, 2012), deve-se modelar a madeira na geometria adequada à acústica do ambiente, e para isso utiliza-se uma madeira de boa trabalhabilidade, grã direita, boa estabilidade dimensional, e bom acabamento. Com base no exposto o presente trabalho tem por objetivo analisar o desempenho acústico de painéis de gesso incorporados com fibras de celulose

\section{Material e métodos}

Os insumos utilizados para a produção dos painéis acústicos foram: rejeitos da etapa de branqueamento de uma indústria de papel e celulose, e gesso. O rejeito proveniente da indústria de papel e celulose foi quantificado diariamente como demonstrado na tabela 1. 
Araujo et al.: Desempenho acústico de painéis de gesso incorporados ...

Tabela 1 - Quantificação diária de rejeitos da indústria de papel e celulose

\begin{tabular}{l|c|c|c}
\hline $\begin{array}{c}\text { Etapas de } \\
\text { branqueamento }\end{array}$ & $\begin{array}{c}\text { Quantidade em } \\
\text { toneladas que entra em } \\
\text { cada processo }\end{array}$ & $\begin{array}{c}\text { Rendimento de cada } \\
\text { processo (\%) }\end{array}$ & \multirow{2}{*}{16,4} \\
\hline \begin{tabular}{c|c} 
Estágio O/O de \\
branqueamento
\end{tabular} & 746 & 97,8 & 14,6 \\
Estágio A/D & 729,6 & 98,7 & 9,3 \\
Estágio (E+P) & 715 & 99,2 & 5,7 \\
Estágio final D & 705,7 & & 46 \\
Polpa branqueada & 700 & & 4 \\
Rejeitos & &
\end{tabular}

\subsection{Metodologia de produção dos Painéis}

Os rejeitos da indústria de papel e celulose foram lavados, tratados e secos, para evitar sua biodegradação e foram submetidos às seguintes etapas:

Mediu-se um volume de material em um balde de 4 litros, revestido com um saco especial para lavagem de polpas. Em seguida adiciona-se $5 \mathrm{ml}$ de água sanitária em 1 litro de água deionizada. Procedeu-se a lavagem e centrifugação, e por fim secagem ao ar livre.

Os painéis acústicos foram produzidos em moldes nos diferentes formatos e nas dimensões desejadas a sua utilização. Mas essencialmente nas composições descritas na tabela 2 .

Tabela 2 - Composição do painel

\begin{tabular}{|c|c|c|}
\hline Matéria-prima & Composição em volume 1 & Composição em volume 2 \\
\hline $\begin{array}{l}\text { Rejeito da indústria de } \\
\text { papel de celulose }\end{array}$ & $50 \%$ do recipiente & $75 \%$ do recipiente \\
\hline Gesso & $50 \%$ do recipiente & $25 \%$ do recipiente \\
\hline
\end{tabular}

\subsection{Confecção dos corpos de prova}

Os corpos de prova foram confeccionados com um diâmetro em torno de $30 \mathrm{~mm}$ (Figura 01). Para a confecção dos mesmos foram utilizados copos descartáveis como recipiente padrão de volume, um recipiente maior para a mistura, e um gabarito, molde padrão em madeira com 8 furos para colocar a massa.

Após, lavagem, tratamento com cloro, e secagem da polpa celulósica os corpos de prova foram confeccionados nas seguintes composições: $50 \%$ do recipiente de polpa+ $50 \%$ do recipiente de gesso+ $50 \%$ do recipiente de água.

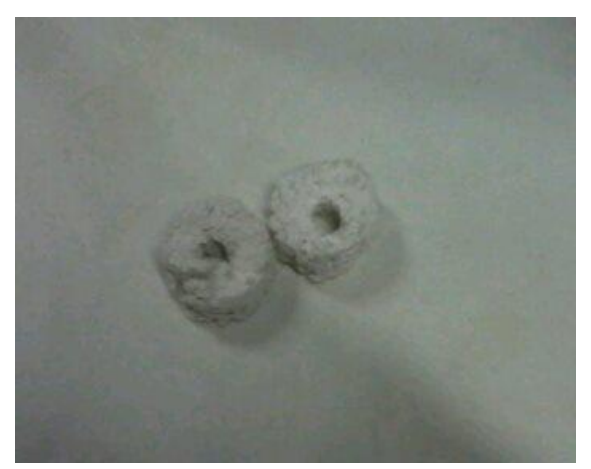

Figura 1- Corpo de prova confeccionado com a composição 1

REGET - V. 20, n. 1, jan.- abr. 2016, p.456-463 


\subsection{Metodologia para Medição}

Os corpos de prova foram fixados numa da extremidade do tubo de impedância acústica, e o microfone foi introduzido pelo orifício central do corpo de prova atravessando até a outra extremidade, que fica aberta para o oscilador de frequência. Os valores foram obtidos na forma gráfica com o Programa Acústica XP-Version 2.0, e a absorção acústica é calculada com os valores de máximo (pico) e de mínimo(vale) do gráfico através da Equação 1:

$$
\alpha_{0}=1-\left(\frac{\beta-1}{\beta+1}\right)^{2}=\frac{4 \beta}{(\beta+1)^{2}}, \beta=\frac{p_{\max }}{p_{\min }}
$$

\section{Onde:}

\section{Equação 1.}
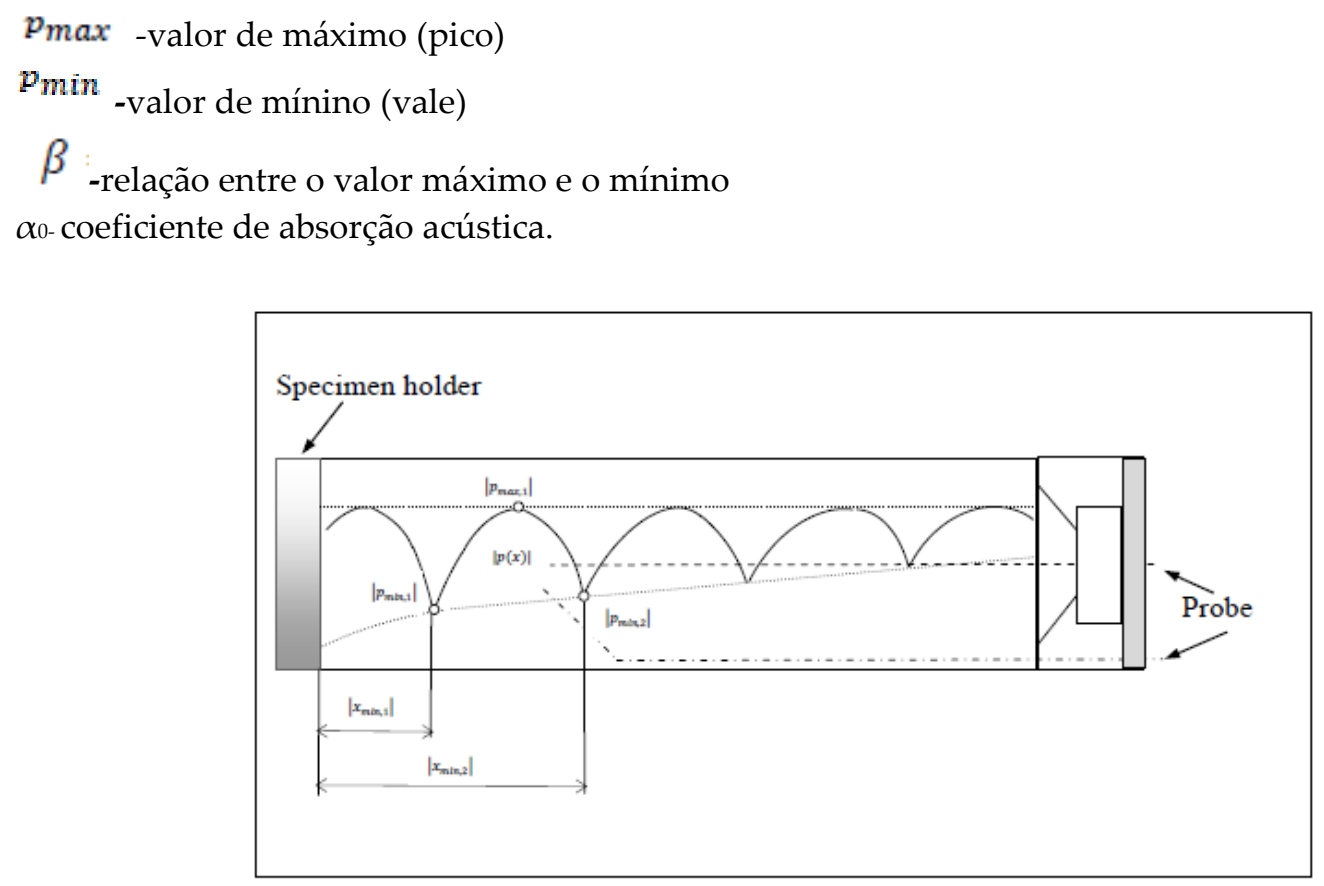

Figura 2- Medição

\section{Resultados}

Para obtenção dos gráficos pelo programa do computador fixou-se uma distância do microfone até a fonte emissora da onda de $100 \mathrm{~mm}$. O corpo de prova ficou a uma distância da fonte de $1 \mathrm{~m}$. Também foi fixado o valor de $350 \mathrm{~Hz}$ no oscilador de frequência.

O programa forneceu os gráficos para cada corpo de prova, e o valor de máximo (pico) e o de mínimo (vale), a média de picos e vales obtidos nos ensaios estão apresentados na tabela 2:

Tabela 2- Valores de mínimo de e de máximo

\begin{tabular}{c|l|l}
\hline $\begin{array}{c}\text { CP (corpo de prova) } \\
\text { Composição 1 }\end{array}$ & & \multicolumn{1}{c}{ Vale } \\
\hline Média & 100,04 & $-100,21$ \\
\hline $\begin{array}{c}\text { CP (corpo de prova) } \\
\text { /Composição 2 }\end{array}$ & Pico & Vale \\
\hline Média & 100,21 & $-100,13$ \\
\hline
\end{tabular}


Os gráficos fornecidos pelo programa possuem o seguinte aspecto, e praticamente não houve variação em seu formato para os diferentes corpos de prova, Figura 03 e 04.

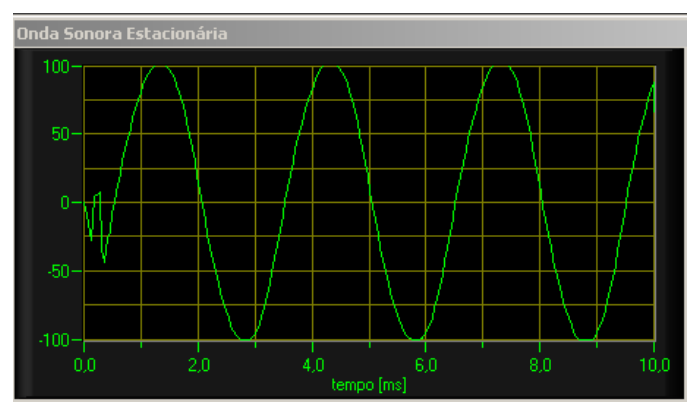

Figura 03- composição 1

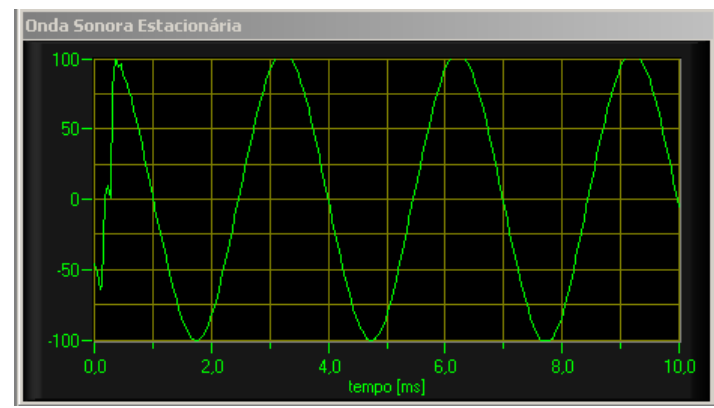

Figura 04- Composição 2

E através da equação 1, pode -se calcular o $\beta$ e em seguida o coeficiente de absorção $\alpha$.

$$
\alpha_{0}=1-\left(\frac{\beta-1}{\beta+1}\right)^{2}=\frac{4 \beta}{(\beta+1)^{2}}, \beta=\frac{p_{\max }}{p_{\min }}
$$

O coeficiente de absorção $\alpha$ é o determinante para um material de boa absorção acústica. O valor calculado está apresentado na tabela 2.

Tabela 3- Coeficiente de absorção

\begin{tabular}{c|c}
\hline $\begin{array}{c}\text { CP (corpo de prova) } \\
\text { Composição 1 }\end{array}$ & Pico \\
\hline Média & 0,99 \\
\hline $\begin{array}{c}\text { CP (corpo de prova) } \\
\text { Composição 2 }\end{array}$ & Pico \\
\hline Média & 0,99 \\
\hline
\end{tabular}

Em ambas as composições os valores do coeficiente de absorção foram satisfatórios, tendo em vista que este deve variar entre 0 e 1, sendo que quanto mais próximo de 1 maior absorção do som pelo material.

O painel de composição 2 (75\%polpa e 25\%gesso) obteve mesmo valor de coeficiente de absorção acústica que a composição 1. Sendo, portanto, viável a produção em larga escala da composição 1, pois a 2 deixou o painel quebradiço dificultando sua instalação nos locais de utilização, assim a maior empregabilidade dessa composição seria para o enchimento de paredes do tipo drywall. 


\section{Conclusões}

Com base nos resultados, pode-se inferir as seguintes conclusões: a produção do painel de composição 2 seria melhor empregada para enchimento de paredes por apresentar baixa resistência durante o manuseio (quebradiço), portanto, a composição 1 é a mais adequada para tetos, e revestimento já que apresentou um bom desempenho durante manuseio, e possui o mesmo valor de coeficiente de absorção acústica que o produzido com composição 2. Dessa maneira a agregação de fibras de celulose em painéis de gesso apresentam grande potencial, trazendo benefícios e aumentando o desempenho acústico do mesmo.

\section{Referências}

ASSOCIAÇÃO BRASILEIRA DE NORMAS TÉCNICAS - ABNTb. NBR 13207 - Gesso para construção civil - classificação. Rio de Janeiro: ABNT, 1994.

ASSOCIAÇÃO BRASILEIRA DE NORMAS TÉCNICAS - ABNT. NBR 10004 - Resíduos

sólidos - classificação. Rio de Janeiro: ABNT, 2004.

BALTAR, C. A. M; BASTOS, F. F; LUZ, A. B. Gipsita-Comunicação técnica elaborada para edição do livro Rochas e Minerais Industriais: Uso e Especificações. P449-470, CETEM, Rio de Janeiro, 2005.

CAZELOTO, K; TAMANINI, C. A. M. Acústica para teatros. AKRÓPOLIS-Revista de Ciências Humanas da UNIPAR, v.11, n.3, Umuarama, 2003.

CHEN, H.C. et. al. Effects of wood particle size and mixing ratios of hdpe on the properties of the composites. European Journal of Wood and Wood Products, Heidelberg, v. 64, n. 3, p. 172-177, dez. 2006.

IBAMA, Geo Brasil 2002 - Perspectivas do Meio Ambiente no Brasil Organizado por Thereza Cristina Carvalho Santos e João Batista Drummond Câmara. - Brasília: Edições IBAMA. Disponível em: $<$ http://www.uff.academia.edu/TherezaCarvalho/Papers/274499/GEO-Brasil-2002-Perspectivas-DoMeio-Ambiente>. Acesso em: mar. 2013.

LEVY NETO, F. PARDINI, L. C. Compósitos estruturais: ciência e tecnologia. 1. ed. São Paulo: Edgard Blücher. 2006. Cap. 3.

LYRA SOBRINHO, A. C. D. et. al. Gipsita. In: Balanço Mineral Brasileiro 2001. Disponível em: $<$ http://www.dnpm.gov.br/assets/galeriadocumento/balanco mineral2001/gipsita.pdf.> Acesso em: 14 out. 2011. 
MAGALHÃES, A. C. T. V. Estudo de fibras vegetais, mucilagem de cacto e gesso em componentes construtivos. Dissertação de mestrado em Arquitetura e Urbanismo, Área de Tecnologia, Universidade de Brasília, Brasília/DF, 2009.

METHA, P. Kumar; MONTEIRO, P. J. M. Concreto: estrutura, propriedades e

Materiais. 573p. ISBN: 85-7266-040-2. São Paulo: Pini, 1994.

METHA, M. J. J.; ROCAFORT, J. Architectural acoustics. Principles and design. Merril Prentice-Hall. New Jersey, 1999.

MORESCHI, Prof. Dr. João Carlos. Propriedades da madeira. Disponível em: $<$ http://www.madeira.ufpr.br/disciplinasmoreschi/APOSTILA-PROPRIEDADESDAMADEIRA2012.pdf $>$. Acesso em: 23 nov. 2012.

OLIVEIRA, M. P. Materiais compósitos à base de gesso contendo EVA (Etileno Acetato de Vinila) e Vermiculita: Otimização de misturas e propriedades termomecânicas. Tese de doutorado . Universidade Federal da Paraíba, 196p, João Pessoa-Paraíba, 2009.

PATRAQUIM, K. J.; LUZ, P. F. C. Painéis acústicos de design inovador. Universidade de Coimbra. Portugal, 2008. 